\title{
In Vitro and In Vivo Antiplasmodial Activity of Three Rwandan Medicinal Plants and Identification of Their Active Compounds
}

Authors

Affiliations
Raymond Muganga ${ }^{1,2}$, Luc Angenot ${ }^{2}$, Monique Tits ${ }^{2}$, Michel Frédérich ${ }^{2}$

${ }^{1}$ National University of Rwanda, Faculty of Medicine, Department of Pharmacy, Butare, Rwanda

${ }^{2}$ Université de Liège, CIRM, Laboratoire de Pharmacognosie, Liège, Belgium

\author{
Key words \\ - Fuerstia africana \\ - Lamiaceae \\ - Terminalia mollis \\ - Combretaceae \\ - Zanthoxylum chalybeum \\ - Rutaceae \\ - ellagic acid \\ - nitidine \\ in vivo antiplasmodial activity
}

received June 5,2013

revised February 14, 2014

accepted March 2, 2014

\section{Bibliography}

DOI http://dx.doi.org/

10.1055/s-0034-1368322

Published online April 7, 2014

Planta Med 2014; 80: 482-489

(c) Georg Thieme Verlag KG

Stuttgart · New York .

ISSN 0032-0943

\section{Correspondence}

Prof Michel Frédérich

Université de Liège, CIRM

Laboratoire de Pharmacognosie,

CHU B36

Av Hopital 1, B36

4000 Liège

Belgium

Phone: + 3243664330

Fax: + 3243664332

m.frederich@ulg.ac.be

\section{Abstract \\ $\nabla$}

In our previous study, we reported the interesting in vitro antiplasmodial activity of some Rwandan plant extracts. This gave rise to the need for these extracts to also be evaluated in vivo and to identify the compounds responsible for their antiplasmodial activity. The aim of our study was, on the one hand, to evaluate the antiplasmodial activity in vivo and the safety of the selected Rwandan medicinal plants used in the treatment of malaria, with the objective of promoting the development of improved traditional medicines and, on the other hand, to identify the active ingredients in the plants. Plant extracts were selected according to their selectivity index. The in vivo antiplasmodial activity of aqueous, methanolic, and dichloromethane extracts was then evaluated using the classical 4-day suppressive test on Plasmodium berghei infected mice. The activity of the plant extracts was estimated by measuring the percentage of parasitemia reduction, and the survival of the experimental animals was recorded. A bioguided fractionation was performed for the most promising plants, in terms of antiplasmodial activity, in order to isolate active compounds identified by means of spectroscopic and spectrometric methods. The highest level of antiplasmodial activity was observed with the methanolic extract

\section{Introduction}

Malaria remains a major public health problem, especially in subtropical regions. In 2010, approximately 3.3 billion people worldwide were exposed to malaria. The highest risk is in the sub-Saharan Africa regions where approximately $81 \%$ of cases and $91 \%$ of deaths occurred in that year, mostly in children under five years of age and in pregnant women [1]. The rise and spread of the resistance of Plasmodium falciparum malaria to of Fuerstia africana (> 70\%) on days 4 and 7 posttreatment after intraperitoneal injection and on day 7 using oral administration. After oral administration, the level of parasitemia reduction observed on day 4 post-infection was $44 \%$ and $37 \%$ with the aqueous extract of Terminalia mollis and Zanthoxylum chalybeum, respectively. However, the $Z$. chalybeum extract presented a high level of toxicity after intraperitoneal injection, with no animals surviving on day 1 post-treatment. F. africana, on the other hand, was safer with $40 \%$ mouse survival on day 20 post-treatment. Ferruginol is already known as the active ingredient in F. Africana, and ellagic acid ( $\mathrm{IC}_{50}=175 \mathrm{ng} / \mathrm{mL}$ ) and nitidine ( $\mathrm{IC}_{50}=77.5 \mathrm{ng} / \mathrm{mL}$ ) were identified as the main active constituents of $T$. mollis and $Z$. chalybeum, respectively. F. africana presented very promising antiplasmodial activity in vivo. Although most of the plants tested showed some level of antiplasmodial activity, some of these plants may be toxic. This study revealed for the first time the role of ellagic acid and nitidine as the main antimalarial compounds in T. mollis and Z. chalybeum, respectively.

Supporting information available online at http://www.thieme-connect.de/ejournals/toc/ plantamedica

chloroquine and sulfadoxine-pyrimethamine, [2] as well as the resistance of falciparum malaria vectors to pyrethroids (insecticides used to prevent malaria in endemic regions), presents a serious challenge, especially in developing countries such as Rwanda [1]. It is therefore imperative that new antimalarial drugs be designed. Medicinal plants constitute a promising source of new drugs and there is now a real interest worldwide in antiplasmodial plants [3]. Many plant extracts have exhibited early promising antiplasmodial activity 


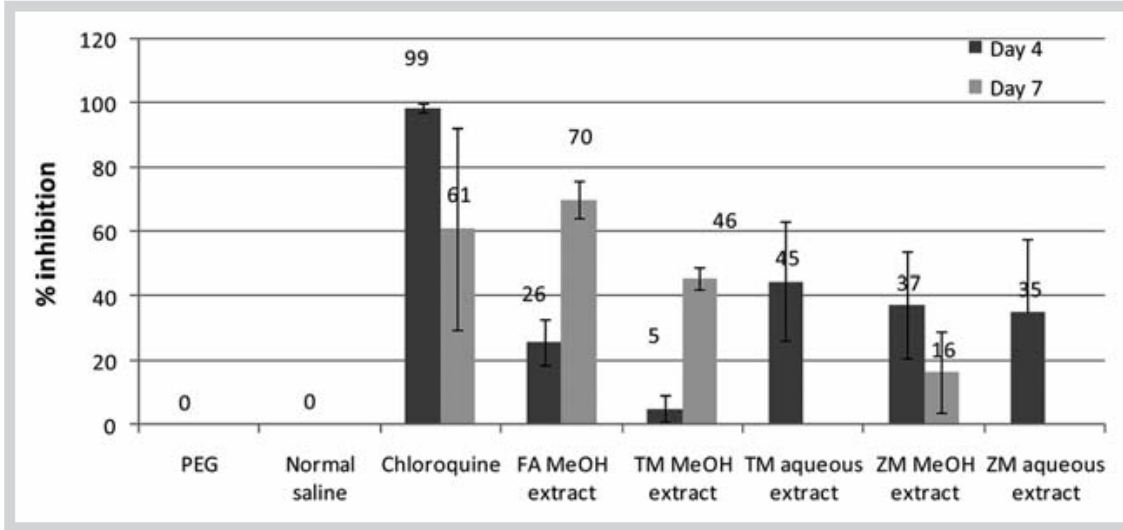

Fig. 1 Parasitemia reduction (\%) of methanol and aqueous plant extracts in mice infected by $P$. berghei. Results of in vivo testing on parasitemia reduction in mice infected by $P$. berghei. PEG (polyethylene glycol) and normal saline were used as the negative control and chloroquine $4 \mathrm{mg} / \mathrm{kg}$ as the positive control. Mice $(n=5)$ received $300 \mathrm{mg} / \mathrm{kg}$ of methanolic orally and an aqueous extract of $T$. mollis (root bark) and Z. chalybeum (root bark), and a methanolic extract of $F$. africana (leaf and stem), separately for four days. The percentage of parasitemia reduction indicated at the top of each column was calculated for each plant sample versus the parasitemia in the control group taken as $100 \%$. FA, F. africana; TM, T. mollis; ZC, Z. chalybeum.

\begin{tabular}{|c|c|c|c|}
\hline \multirow[t]{2}{*}{ Sample } & \multirow[t]{2}{*}{ Extract tested } & \multicolumn{2}{|c|}{ Mouse survival time (day) $(n=5)$} \\
\hline & & $\begin{array}{l}\text { Oral } \\
\text { administration }\end{array}$ & $\begin{array}{l}\text { Intraperitoneal } \\
\text { administration }\end{array}$ \\
\hline F. africana (L \& S) & Methanol extract & $11.8 \pm 6.7$ & $17.6 \pm 1.2$ \\
\hline \multirow[t]{3}{*}{ T. mollis (RB) } & Methanol extract & $7.8 \pm 0.4$ & $6.2 \pm 7.4$ \\
\hline & Aqueous extract & $8.2 \pm 6.1$ & nd \\
\hline & Aqueous extract free of tannins & nd & $9.2 \pm 3.9$ \\
\hline \multirow[t]{2}{*}{ Z. chalybeum (RB) } & Methanol extract & $14.2 \pm 6.0$ & 0 \\
\hline & Aqueous extract & $10.6 \pm 5.3$ & nd \\
\hline PEG & nd & $10.5 \pm 5.7$ & nd \\
\hline $\mathrm{NaCl} 0.9 \%$ & nd & nd & $13 \pm 8$ \\
\hline Chloroquine & nd & $>20$ & $>20$ \\
\hline
\end{tabular}

Table 1 Viability of mice infected by $P$. berghei after treatment with plant extracts via oral and intraperitoneal administration. The number of dead mice was recorded daily in all study groups to determine the average survival time of the infected mice after treatment.

L: leaf; S: stem; R: root; B: bark; RB: root bark; nd: not determined

in vitro and they may or may not prove to be more active in vivo. In our previous report, some medicinal plants used in Rwanda to treat malaria showed interesting antiplasmodial activity in vitro [4]. However, before those plants can be recommended in the treatment of malaria, their activity and safety needs to be evaluated in vivo. To this end, in the present study, three plants, Fuerstia africana T.C.E. Fries (Lamiaceae), Terminalia mollis M.A. Lawson (Combretaceae), and Zanthoxylum chalybeum Engl. (Rutaceae), were selected for in vivo antiplasmodial testing based on their antiplasmodial and cytotoxic activity. These plants are traditionally used in many countries and the antiplasmodial activity of other Fuerstia, Terminalia, and Zanthoxylum species is already well known [5-8]. Determination of the active ingredient responsible for the antiplasmodial activity of these plants constitutes an important step before they may be recommended in the treatment of malaria. As F. africana has already been widely studied and its active compounds already isolated, we decided to focus our bioguided fractionation on the two other plants of interest, Z. chalybeum and T. mollis. These two plant species were submitted to a phytochemical study in order to isolate and identify their antimalarial compounds. The present study reports the in vivo antiplasmodial activity of $F$. africana, T. mollis, and $Z$. chalybeum against Plasmodium berghei in mice and the identification of the active ingredients responsible for the antiplasmodial activity of the last two of these plant species.

\section{Results \\ $\nabla$}

In our previous report [4], some plant extracts exhibited an interesting level of antiplasmodial activity in vitro with an $\mathrm{IC}_{50}$ $<15 \mu \mathrm{g} / \mathrm{mL}$. The cytotoxic activity of those plant samples was then evaluated and the selectivity index determined. Based on their selectivity index, three plant extracts, methanol, leaf, and stem extract of $F$. africana, and the methanolic root bark extract of $Z$. chalybeum and T. mollis were selected for in vivo testing using oral and intraperitoneal administration. Of the extracts administered via the oral route, on day 4 post-treatment, the methanolic extract of $Z$. chalybeum exhibited the best parasitemia reduction (37\%) followed by the methanolic extract of $F$. africana (25\%). On day 7 , the highest level of parasitemia reduction was obtained with the methanolic extract of F. africana (70\%) followed by the methanolic extract of T. mollis (45\%) ( Fig. 1). Of the extracts administered via the intraperitoneal route, only the F. africana extract gave good results, with a parasitemia reduction level of $74 \%$ and $71 \%$ on days 4 and 7 , respectively. On the other hand, mice that received $Z$. chalybeum did not survive for more than one day post-treatment ( $\bullet$ Table 1 ).

The antiplasmodial activity of $F$. africana is already known. A previous study reported the in vitro antiplasmodial and cytotoxic activity of ferruginol, the active ingredient in F. africana [5]. However, results showed that the plant presented a good mouse survival time, indicating that ferruginol toxicity in the mouse may be weak. Other constituents of $F$. africana may also modulate its activity. Considering that the antiplasmodial compound of F. africana has already been identified and is known to be cytotoxic, we decided not to study the phytochemistry of this plant, but to in- 


\begin{tabular}{|c|c|c|}
\hline \multirow[t]{2}{*}{ Sample } & \multicolumn{2}{|c|}{ Hemolysis (\%) } \\
\hline & $100 \mu \mathrm{g} / \mathrm{mL}$ & $200 \mu \mathrm{g} / \mathrm{mL}$ \\
\hline T. mollis crude methanol extract & $0.05 \pm 0.03$ & $0.11 \pm 0.40$ \\
\hline T. mollis crude aqueous extract & $0.08 \pm 0.06$ & $0.03 \pm 0.02$ \\
\hline Z. chalybeum crude methanol extract & $0.17 \pm 0.15$ & $0.39 \pm 0.04$ \\
\hline
\end{tabular}

Table 2 Percentage of hemolysis with $T$. mollis and $Z$. chalybeum root bark extracts.

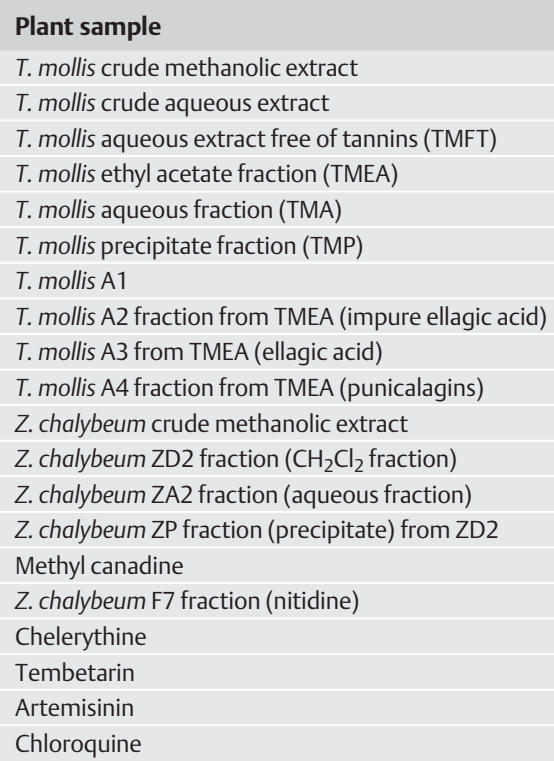

$\begin{array}{cl}3 \mathbf{3 D}\left(\mathbf{I} \mathbf{C}_{\mathbf{5 0}} \mu \mathrm{g} / \mathrm{mL}\right) & \text { F32 }\left(\mathbf{I} \mathbf{C}_{\mathbf{5 0}} \mu \mathrm{gg} / \mathrm{mL}\right) \\ 3.84 \pm 1.23 & 3.42 \pm 0.77 \\ 4.66 \pm 0.89 & 12.31 \pm 1.18 \\ 25.77 \pm 4.89 & \text { nd } \\ 2.10 \pm 0.48 & \text { nd } \\ 19.72 \pm 4.86 & \text { nd } \\ 39.71 \pm 2.18 & \text { nd } \\ >50 & \text { nd } \\ 0.75 \pm 0.06 & \text { nd } \\ 0.17 \pm 0.17 & 0.12 \pm 0.08 \\ >50 & >50 \\ 6.18 \pm 1.23 & \text { nd } \\ 4.81 \pm 0.26 & \text { nd } \\ 14.37 \pm 5.49 & \text { nd } \\ 22.53 \pm 2.37 & \text { nd } \\ 2.01 \pm 1.10 & \text { nd } \\ 0.07774 \pm 0.01 & 0.027 \pm 0.013 \\ 1.35 \pm 0.80 & \text { nd } \\ 2.01 \pm 0.74 & \text { nd } \\ 0.0052 \pm 0.0002 & \text { nd } 0.0030 \pm 0.0003 \\ 0.0017 \pm 0.0004 & \text { nd }\end{array}$

Table 3 In vitro antiplasmodial activity (IC 50 values) of $T$. mollis and $Z$. chalybeum root bark extracts, fractions, and isolated compounds on two $P$. falciparum strains. Data are expressed as mean $\pm S D, n \geq 3$.

nd: not determined

stead focus the remainder of the present study on the other two plants, Z. chalybeum and T. mollis.

As methanol extracts of $Z$. chalybeum and T. mollis did not exhibit a high level of activity in vivo and taking into consideration the fact that traditional healers use water as the solvent in the preparation of these plants, the aqueous extracts of $T$. mollis and $Z$. chalybeum, active in vitro, were also assessed for their in vivo antiplasmodial activity (per oral administration). On day 4 , the activity of the aqueous and methanolic extracts of $Z$. chalybeum was quite similar (parasitemia reduction of 34 and $37 \%$, respectively), whereas the aqueous extract of $T$. mollis was more active (44\%) than the methanolic extract (5\%) ( Fig. 1, Table 1). Methanolic root bark extracts of $T$. mollis and $Z$. chalybeum have been shown to present a reasonable level of antiplasmodial activity in vitro $\left(\mathrm{IC}_{50}<15 \mu \mathrm{g} / \mathrm{mL}\right.$ ) [4]. However, in this present study, these extracts were found to be less active in vivo, suggesting that the oral absorption of active ingredients from those plants may be poor.

The in vitro hemolysis test was done only on two plants, $Z$. chalybeum and T. mollis. The percentage of hemolysis was found to be 0.05 and 0.08 , respectively, for the methanolic and aqueous root bark extracts of T. mollis at a concentration of $100 \mu \mathrm{g} / \mathrm{mL}$. The level of hemolysis was $0.11 \%$ and $0.03 \%$ for the same extracts at a concentration of $200 \mu \mathrm{g} / \mathrm{mL}$. The methanol root bark extract of $Z$. chalybeum exhibited a percentage of hemolysis of 0.17 and 0.39 at a concentration of 100 and $200 \mu \mathrm{g} / \mathrm{mL}$, respectively ( Table 2). All the tested T. mollis root bark extracts showed antiplasmodial activity in vitro and the best activity was found with the methanolic extract, which was chosen for the bioguided fractionation. After liquid-liquid partition, the ethyl acetate fraction (TMEA) was found to be more active $\left(\mathrm{IC}_{50}=2.10 \mu \mathrm{g} / \mathrm{mL}\right.$ ) than the aqueous and insoluble fractions $\left(\mathrm{IC}_{50}=4.66 \mu \mathrm{g} / \mathrm{mL}\right.$ and $39.71 \mu \mathrm{g} / \mathrm{mL}$, respectively). The fractionation of TMEA yielded different fractions from which compound $\mathbf{A} 3$ was isolated (fraction: 87-88). This compound presented a very high level of activity, with an $\mathrm{IC}_{50}=0.175 \mu \mathrm{g} / \mathrm{mL}$ ( Table 3). Fraction A2 also presented a very significant level of activity $\left(\mathrm{IC}_{50}=0.75 \mu \mathrm{g} / \mathrm{mL}\right)$ and its further analysis revealed that it was a semi-pure fraction containing additional A3 ( Table 3). The spectral data of all the isolated constituents were compared with their corresponding references. Compound A1 was identified as an ellagic acid derivative and was found to be inactive against $P$. falciparum strain 3D7. Compound $A 3$, found to be very active against $P$. falciparum, was identified as ellagic acid with a purity of $98 \%$ ( Fig. 2). Fraction A4 was identified as a mixture of punicalagin A \& B (anomeric isomers) by comparing their spectral data with those of a commercial sample ( Fig. 3). The commercial sample was a mixture of punicalagin A (38.1\%) and punicalagin B (61.1\%). Gallic acid and some condensed tannins, such as catechin, gallocatechin, and epigallocatechin, also present in T. mollis, were found to have a lower level of antiplasmodial activity, ( $\mathrm{IC}_{50}>25 \mu \mathrm{g} / \mathrm{mL}$ ) than the one found for ellagic acid [8]. Consequently, ellagic acid can be identified as the main antiplasmodial constituent with the other compounds present in T. mollis and possibly serves to reinforce its antiplasmodial activity.

For $Z$. chalybeum, after alkalinization and extraction of the aqueous fraction by dichloromethane, the best antiplasmodial activity was obtained with the organic fraction ZD2 $\left(\mathrm{IC}_{50}=4.8 \pm 0.26 \mu \mathrm{g} /\right.$ $\mathrm{mL}$ ). A bioguided preparative HPLC of this organic fraction yielded different fractions, of which fraction 7 (F7), a yellow needle-like crystal, was found to be the most active, with $\mathrm{IC}_{50} \mathrm{~S}=77.74$ and $27 \mathrm{ng} / \mathrm{mL}$, respectively, on the $P$. falciparum 
strains 3D7 and F32. Based on NMR and mass spectrometry spectra, the active compound was identified as nitidine ( $\bullet$ Fig. 4). The yield of nitidine isolated from the root bark of $Z$. chalybeum was estimated to be $0.002 \%$ and its purity around $96.53 \%$. Methyl canadine, chelerythine, and tembetarin were also isolated from the plant and were found to exhibit an $\mathrm{IC}_{50}>1 \mu \mathrm{g} / \mathrm{mL}$ ( $\bullet$ Table 3 ).

\section{Discussion}

$\nabla$

The aqueous crude extract of $T$. mollis exhibited a high level of antiplasmodial activity $\left(\mathrm{IC}_{50}=4.66 \mu \mathrm{g} / \mathrm{mL}\right)$ against $P$. falciparum strain 3D7, supporting the use of this plant in traditional medicine. However, a previous study reported a weak level of activity of the aqueous extract from this plant [4]. This difference may be explained by the fact that the samples used in the two studies were different. Furthermore, a significant difference in terms of activity was observed here between samples of $T$. mollis collected during the summer period and those collected during the rainy season. It has already been observed that the time of collection and the locality of the plant material may play a major role in its beneficial properties [4].

Concerning in vivo activity, the majority of the mice treated intraperitoneally with $T$. mollis extract died on day 2 post-treatment and only one mouse survived until day 20 post-treatment, suggesting that the plant extract is toxic in mice. The survival time for mice treated orally with the methanol or water extract was also lower than for the control mice, indicating, again, a potential toxicity. However, on day 4 post-infection, the mice treated orally with $T$. mollis exhibited a significant decrease in their parasitemia, indicating a verifiable activity against the parasite. The toxicity of Terminalia species has been previously reported and may be attributed to saponins [9] or to hydrolysable tannins [10]. We therefore wanted to verify whether hydrolysable tannins present in T. mollis, such as punicalagin and its derivatives, were responsible for this toxicity. For this purpose, a methanolic extract free of hydrolysable tannins was made using a size exclusion column (Sephadex) and was then administered intraperitoneally to mice. The majority of the mice (60\%) treated with this preparation free of hydrolysable tannins died within 6 days after infection, meaning that other constituents may contribute to the toxicity of the plant. Moreover, a condensed tannin called terminalin (MW = 603 ) isolated from T. oblongata has been reported to be toxic [11] and this toxic compound may also be present in other Terminalia species such as T. mollis. Unfortunately, we were not able to verify the presence of this toxic condensed tannin in our preparation, as the compound is not commercialized and we could not identify it in the extract. The reason why the toxicity of the plant was previously attributed to its saponin content [9] is that saponins have a deleterious hemolyzing effect on circulating red blood cells [12].

However, in the present study, hemolysis testing carried out on aqueous and methanolic extracts of $T$. mollis at a concentration of $200 \mu \mathrm{g} / \mathrm{mL}$ revealed no hemolytic effect from the extracts ( Table 2). This indicates that at the concentrations presenting antiplasmodial activity, extracts of T. mollis exhibited no toxicity towards erythrocytes, suggesting that at a therapeutic dose level, no toxicity of the plant caused by its saponins is to be expected. Furthermore, after oral administration of $300 \mathrm{mg} / \mathrm{kg}$ methanolic root bark extract of $T$. mollis per day for 3 days, no acute toxicity was observed in uninfected mice. This means that malaria caused by $P$. berghei in mice negatively influences mouse survival time.
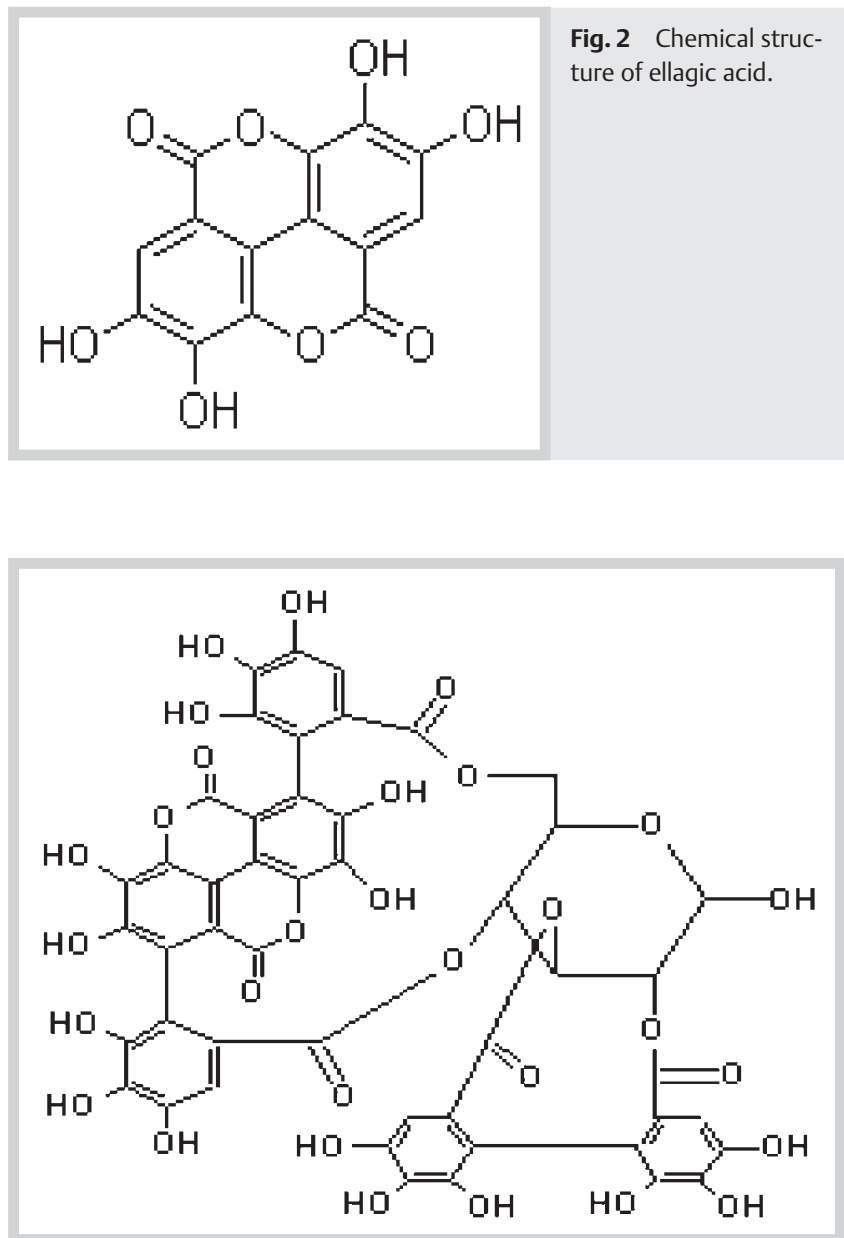

Fig. 3 Chemical structure of punicalagins (anomeric isomers A \& B).

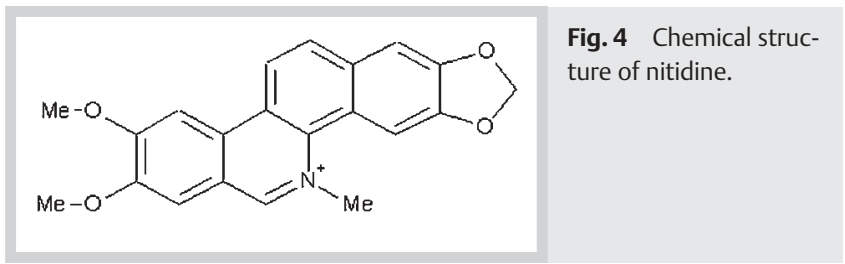

Bioguided fractionation led to the identification of ellagic acid as an active compound ( $\mathrm{IC}_{50}=0.175 \mu \mathrm{g} / \mathrm{mL}$ ), while ellagic acid derivatives were inactive. These results support previous reports in which the important role of free hydroxyl groups in the antiplasmodial activity of ellagic acid was observed [13]. The in vitro antiplasmodial activity of ellagic acid is already known [14] and our results are in accordance with those already found $\left(\mathrm{IC}_{50}\right.$ between 90 and $175 \mathrm{ng} / \mathrm{mL}$ ). In this study, ellagic acid was found in T. mollis root bark in an aglycone form (free form). Most of the time, ellagic acid is present in a conjugated form with a glycoside moiety, and it is uncommon for it to be found in its free form in nature [15]. Fraction A4, the mixture of punicalagin A \& B, did not present any interesting antiplasmodial activity in either of the $P$. falciparum strains. In contrast, previous studies have reported the antiplasmodial activity of punicalagin, although without specifying which form (punicalagin A or B), was the active constituent [16]. Asres et al. reported that punicalagin was active against $P$. falcipa- 
rum strain $3 \mathrm{D} 7\left(\mathrm{IC}_{50}=27.73 \mu \mathrm{g} / \mathrm{mL}\right)$ [17]. This level of punicalagin activity is very low for a pure compound and should be qualified as negligible compared to that found for other pure compounds such as ellagic acid. Punicalagin is a hydrolysable polyphenolic compound [18] found in plants. Commonly called ellagitanin, punicalagin plays the physiological role of protection against microbial decay [19]. Various biological activities of punicalagin have been reported: antioxidant, anti-inflammatory, anti-genotoxic, antiviral [20-22], and hepatoprotective [23]. However, there has been a great deal of discussion about the toxicity of this compound, as it may provoke liver necrosis and nephrotoxicity [11, $24,25]$. Further studies are needed to prove the safety of punicalagin in humans. In the present study, the crude aqueous extract free of tannin was also found to be active, suggesting that the active ingredient(s) is/are not totally adsorbed by hide powder. HPLC analysis of this extract demonstrated that ellagic acid was still present, whereas punicalagin and its analogs were almost absent.

Ellagic acid has been shown to present synergistic activity with other antimalarial drugs, such as chloroquine, atovaquone, mefloquine, and artesunate, and a slight antagonism against artemisinin [14]. The mechanism of action of ellagic acid on P. falciparum is not very well known. Some researchers have suggested that since ellagic acid has the ability to form a $\pi-\pi$ complex [26], it may act at the mature trophozoite and young schizont stage of the erythrocytic life cycle by inhibiting $\beta$-hematin formation in the parasite in the same way as aminoquinoline antimalarial agents such as chloroquine [27]. Although ellagic acid is very active against malaria, its bioavailability is low. Indeed, ellagic acid exhibits poor absorption (less than $1 \%$ ) and is rapidly excreted after oral administration [28]. This may explain why, in the present study, the percentage of inhibition of the plant extract in the in vivo test using oral administration was not extremely high. Ellagic acid possesses other beneficial properties, such as anticancer, antimutagenic $[29,30]$, antioxidant, anti-inflammatory [14,31], antiviral [32], and antibacterial activity [19]. The fact that this compound presents antiplasmodial, antioxidant, and anti-inflammatory activity may be an advantage, especially in cases of malaria [33]. Ellagic acid also exhibits cardioprotective activity [34], antiulcer activity [35], and hepatoprotective activity [36]. Moreover, since part of the P. falciparum life cycle occurs in the liver, the hepatoprotective activity of ellagic acid is a real advantage. Nevertheless, galenical or chemical modifications are needed to improve its activity after oral administration.

All mice that received the methanolic root bark extract of $Z$. chalybeum died within 5-10 minutes after intraperitoneal injection, indicating the high toxicity of the extract in mice. The toxicity of Z. chalybeum may result from its quaternary alkaloids [37], in particular candicine, which has already been reported to have a prominent curariform effect, stimulating nicotinic and paralyzing nicotinic actions [38]. Furthermore, just before sudden death, the mice in the present study exhibited convulsions and paralysis, and those symptoms have already been observed in mice after an intra-peritoneal injection of candicine [39]. As for T. mollis, no hemolysis was observed in the present study on erythrocytes with the highest concentrations tested for antiplasmodial activity.

As Z. chalybeum is rich in alkaloids that may contribute to its various therapeutic properties [37], the bioguided fractionation was performed here only on targeted alkaloids. Of all the alkaloids isolated, nitidine exhibited the highest level of antiplasmodial activity $\left(\mathrm{IC}_{50}=0.075 \mu \mathrm{g} / \mathrm{mL}\right.$ ). Nitidine is a quaternary alkaloid al- ready known to be present in $Z$. chalybeum and in the Rutaceae family in general [40-42]. Nitidine was isolated for the first time in Z. nitidium and the compound is responsible for the antiplasmodial activity of many antimalarial remedies $[43,44]$. A previous study reported that the yield of nitidine from the root of $Z$. chalybeum was about $0.0123 \%$ [45]. This yield is higher than that found in the root bark $(0.002 \%)$ in the present study, suggesting that the whole root of the plant contains more nitidine. This also explains why the root of the plant without the bark has also been found to be active against $P$. falciparum $\left(\mathrm{IC}_{50}=7.31 \mu \mathrm{g} / \mathrm{mL}\right.$ ) (data not published). Considered to be a potential anticancer drug, nitidine has been reported to have other therapeutic properties such as antileukemic [40], antimicrobial, anti-inflammatory, analgesic, and anti-HIV [46] activity. In our study, the high level of antiplasmodial activity of nitidine on chloroquine-sensitive $P$. falciparum strains was in accordance with previously reported findings [43, 44]. The slight differences between the $\mathrm{IC}_{50}$ values found in our study in comparison with previous findings may be explained by the fact that different methods were used. In the previous studies, other alkaloids such as methyl canadine, chelerythine, and tembetarin were also isolated from the plant but their activity was shown to be much lower ( IC $_{50}>1 \mu \mathrm{g} / \mathrm{mL}$ ) compared to that of nitidine. Consequently, nitidine could be considered the main antiplasmodial ingredient in $Z$. chalybeum and the other alkaloids, such as chelerythine and methyl canadine, which are already known in the plant [37] and may intervene by synergism in this activity. Nitidine has already been reported to be the active ingredient in another Zanthoxylum species, Z. gilletii [47]. The mechanism of action of nitidine may be due to its ability to inhibit topoisomerase in malaria parasites [43]. However, it has recently been reported that nitidine may possess a chloroquinelike mechanism of action because of its capacity to bind to heme and to inhibit $\beta$-hematin formation [44]. Further investigations regarding nitidine would still be of interest in order to exploit the remarkable antiplasmodial activity of this compound.

\section{Materials and Methods}

$\nabla$

\section{Plant material}

Samples of T. mollis and Z. chalybeum were collected between August and October 2010 from Akagera National Park (South-West Rwanda), whereas the sample of $F$. africana was collected in the same period but from Huye (Southern Province of Rwanda). Each species was identified Dr. Bizuru Elias (Senior Lecturer, Department of Biology, University of Rwanda) and confirmed by Professor Elmar Robbrecht (Botanist of National Botanic Garden of Belgium). A voucher specimen was deposited in the Rwandan National Herbarium at Butare and another at the National Botanic Garden of Belgium at Meise. The voucher numbers are BR0000005087266, BR0000005087167, and BR0000005088850 for Z. chalybeum, T. mollisi, and F. africana, respectively. All samples collected were air-dried at room temperature with no direct sunlight for 3 days. Dried plant samples were then pulverized using an electrical grinder under strict hygienic conditions.

\section{Preparation of plant extracts for in vivo testing}

Crude methanolic and aqueous plant extracts were prepared as described early [4] and then dissolved in polyethylene glycol (PEG), normal saline ( $\mathrm{NaCl} 0.9 \%$ ), or a mixture of $7 \%$ Tween 80 and $3 \%$ ethanol according to their solubility. The last solvent was used for all plant samples administered intraperitoneally. 


\section{In vitro hemolysis with plant extracts}

Methanolic and aqueous root bark extracts of T. mollis and Z. chalybeum at a final concentration of 200 and $100 \mu \mathrm{g} / \mathrm{mL}$ in DMSO (1\%) were tested with $10 \%$ freshly heparinized human blood (A +) in PBS. $190 \mu \mathrm{L}$ of $10 \%$ human blood were added to $10 \mu \mathrm{L}$ of plant extract and the mixture was incubated for $1 \mathrm{~h}$ under constant and slow shaking at room temperature. After incubation, the solutions were centrifuged for $5 \mathrm{~min}$ at $2000 \mathrm{rpm}$ in an Eppendorf centrifuge $5417 \mathrm{R}$. The supernatant was removed and the absorbance (A) of liberated hemoglobin was measured at $550 \mathrm{~nm}$ with a Perkin Elmer Wallac Victor ${ }^{2}$ spectrophotometer. DMSO (20\%) (Sigma-Aldrich), Triton - 100 (20\%), and PBS (Lonza) were used, respectively, as the solvent, positive (100\% hemolysis), and negative control. Each sample was analyzed in triplicate and the mean $\pm \mathrm{SE}$ was calculated. The percentage of hemolysis was calculated as follows:

\% Hemolysis: [(A product - A solvent) /(A Triton - A PBS $)] \times 100$

\section{In vivo antiplasmodial activity}

Permission and approval were obtained for the present study from the University of Liège Ethics Committee on March 19, 2012 (case file number 721). All mice used were SPF (specific pathogen free) females, approximately 4-5 weeks old (18-20 g), and free from Eperythrozoon coccoides and Haemobartonella $\mathrm{mu}$ ris. The mice were obtained from Charles River (France). The parasite used to infect the mice was P. berghei, NK173 strain. In vivo antiplasmodial tests were performed based on the classical 4-day suppressive test as previously reported [48]. Briefly, female Swiss mice (5 mice/group) were infected by P. berghei NK173 four hours before treatment. Treatment doses $(200$ and $300 \mathrm{mg} / \mathrm{kg}$ of plant extract) were given intraperitoneally and orally once daily from day 0 to day 3. On days 4 and 7, thin mouse tail blood smears were prepared and stained with Giemsa. Parasitemia was determined by counting at least 500 erythrocytes under a microscope. Chloroquine diphosphate (Sigma, purity $\geq 98 \%$ ) at $4 \mathrm{mg} / \mathrm{kg}$ doses and physiological serum (To) or PEG were used as the positive control and negative control, respectively. The percentage of parasitemia reduction (activity) was calculated on days 4 and 7 using the following formula [48]:

\%Inhibition $=100-\left\{\frac{\text { Mean parasitemia treated }}{\text { Mean parasitemia control }} \times 100\right\}$

\section{Isolation and identification of antiplasmodial compounds}

In our previous report, the highest level of antiplasmodial activity in T. mollis was found using methanol extract [4], which was then fractionated to isolate active constituents. The crude methanolic root bark extract was obtained by macerating $500 \mathrm{~g}$ of the plant material with $6 \mathrm{~L}$ of methanol for 72 hours at room temperature. Extracts were then evaporated to dryness under reduced pressure and the yield was $38.29 \%$. An aliquot ( $50 \mathrm{~g}$ ) of the methanolic extract was solubilized in a $150-\mathrm{mL}$ mixture of methanol and water $(8: 2)$ and then consecutively extracted with ethyl acetate and water $(150 \mathrm{~mL} \times 3)$. Three fractions were then obtained, TMEA $( \pm 48 \%)$, an aqueous fraction (TMA) $( \pm 38 \%$ ), and a precipitate (TMP) $( \pm 14 \%)$. Fractions were tested for antimalarial activity and the most active fraction was fractionated by preparative high-performance liquid chromatography (HPLC) (Agilent Technologies 1200 series), size exclusion (Fractogel ${ }^{\circledR}$ TSK HW-40 (s) (Merck), and Sephadex ${ }^{\circledR}$ (Sigma-Aldrich) in order to isolate pure compounds, which were also tested. HPLC (reversed phase) was performed using acetonitrile-pure water as the mobile phase in gradient mode and an ODS C18 column Hypersil 250/4.6 mm ( $5 \mu \mathrm{m}$; Alltech) as the stationary phase. Methanol was used to separate the compounds with Fractogel, while ethanol and pure water were used as the eluents for Sephadex. Fractogel was used to obtain an aqueous fraction free of tannins (TMFT), which was used in in vitro and in vivo antiplasmodial tests. Sephadex was used to isolate compounds $\mathbf{A} 1, \mathbf{A} 3$, and fractions A2, A4. Pure compounds were further submitted to NMR and mass spectroscopy in order to determine their chemical structure.

Similarly, the best antiplasmodial activity for $Z$. chalybeum was obtained with the methanolic root bark extract, from which pure compounds were isolated. The powdered root bark of $Z$. chalybeum $(500 \mathrm{~g})$ was extracted with $6 \mathrm{~L}$ of a mixture of methanol and acetic acid (1\%) for 72 hours at room temperature. The solution obtained was concentrated to about $500 \mathrm{~mL}$ and pure water $( \pm 200 \mathrm{ml})$ was added to precipitate pigments. After filtration, the solution was then extracted with dichloromethane to obtain two phases. The aqueous phase (ZA1) was basified by sodium carbonate $(\mathrm{pH} 10)$ and then extracted with dichloromethane. Three fractions were obtained: aqueous fraction (ZA2), organic fraction (ZD2), and an insoluble fraction (ZP), which were subsequently submitted to in vitro antiplasmodial testing. The most active fraction was fractionated using preparative HPLC with acetonitrile and trifluoroacetic acid $0.05 \%$ as the mobile phase in gradient mode and a Pursuit 5 Diphenyl SS $250 \times 4.6 \mathrm{~mm},(5 \mu \mathrm{m})$ (Varian) as the stationary phase. Isolated pure compounds were tested in vitro and their chemical structure was determined using NMR (Bruker Avance $500 \mathrm{MHz}$ DRX 500 spectrometer) and mass spectrometry (Micromass ESI-Q-TOF II instrument). The aqueous fraction was acidified and quaternary alkaloids were precipitated overnight with Mayer's reagent. The next day, the precipitate was rinsed with cold water and then eluted with a mixture of acetone-water-ethanol $(6: 1: 2)$ on an ion exchange resin column (Amberlite ${ }^{\circledR}$ ), which transforms alkaloids into their chloride form. The alkaloid fraction obtained was further fractionated using preparative HPLC, and isolated pure quaternary alkaloids were identified as described above.

\section{Antiplasmodial activity of fractions and pure compounds}

Crude methanolic, aqueous extracts, and different fractions of the plant were submitted to in vitro antiplasmodial testing against two $P$. falciparum strains, 3D7 and F32. The P. falciparum strain F32 was chosen because it originates from Tanzania, a country close to Rwanda, where the plant is used to treat malaria. A parasite culture was carried out as already described [49] and an antiplasmodial activity test was performed according to the method previously reported [4]. Artemisinin (98\% Sigma-Aldrich) and chloroquine (Sigma-Aldrich) were used as references. All samples were tested in triplicate and the results are expressed as mean $\pm S D$.

\section{Supporting information}

HPLC analysis of T. mollis and Z. chalybeum, and nuclear magnetic resonance spectra of ellagic acid and nitidine in DMSO are available as Supporting Information. 


\section{Acknowledgements}

$\nabla$

The authors wish to thank the Ulg-GIGA Unit for facilitating the performance of in vivo tests on mice. The authors are also grateful to J.-N. Wauters, M.J. Cl. Van Heugen, and Mrs. Joëlle Widard for their technical assistance. This study was sponsored by the CUD (Coopération Universitaire au Développement) and by the Belgian National Fund for Scientific Research (FNRS, grant 3.4533.10).

\section{Conflict of Interest}

$\nabla$

The authors declare no conflict of interest.

\section{References}

1 WHO. World malaria report 2011. Geneva: World Health Organization; 2011

2 Ginsburg H, Deharo E. A call for using natural compounds in the development of new antimalarial treatments - an introduction. Malar J 2011; 10: S1

3 Rasoanaivo P, Wright CW, Willcox ML, Gilbert B. Whole plant extracts versus single compounds for the treatment of malaria: synergy and positive interactions. Malar J 2011; 10: S4

4 Muganga R, Angenot L, Tits M, Frédérich M. Antiplasmodial and cytotoxicity of Rwandan medicinal plants used in the treatment of malaria. J Ethnopharmacol 2010; 128: 52-57

5 Koch A, Orljala J, Mutiso PC, Soejarto DD. An antimalarial abietane diterpene from Fuerstia africana T.C.E. Fries. Biochem Syst Ecol 2006; 34: 270-272

6 Pinmai K, Hiriote W, Soonthornchareonnon N, Jongsakul K, Sireeratawong S, Tor-Udom S. In vitro and in vivo antiplasmodial activity and cytotoxicity of water extracts of Phyllanthus emblica, Terminalia chebula, and Terminalia bellerica. J Med Assoc Thai 2010; 93: S120-S126

7 Rukunga GM, Gathirwa JW, Omar SA, Muregi FW, Muthaura CN, Kirira $P G$, Mungai GM, Kofi-Tsekpo WM. Anti-plasmodial activity of the extracts of some Kenyan medicinal plants. J Ethnopharmacol 2009; 121: $282-285$

8 Ramanandraibe V, Grellier P, Martin MT, Deville A, Joyeau R, Ramanitrahasimbola D, Mouray E, Rasoanaivo P, Mambu L. Antiplasmodial phenolic compounds from Piptadenia pervillei. Planta Med 2008; 74: 417421

9 Bulus T, Atawodi SE, Mamman M. Acute toxicity of aqueous extract of Terminalia mollis on rats. ChemClass Journal 2007; 4: 57-60

10 Mbwambo ZH, Moshi MJ, Masimba PJ, Kapingu MC, Nondo RSO. Antimicrobial activity and brine shrimp toxicity of extracts of Terminalia brownii roots and stem. BMC Complem Altern M 2007; 7: 9

11 Oelrichs PB, Pearce CM, Zhu J, Filippich LJ. Isolation and structure determination of terminalin a toxic condensed tannin from Terminalia oblongata. Nat Toxins 1994; 2: 144-150

12 Lacaille-Dubois MA, Wagner $H$. A review of the biological and pharmaceutical activities of saponins. Phytomedicine 1996; 4: 363-386

13 Simões-Pires CA, Vargas S, Marston A, Ioset JR, Paulo MQ Matheeussen A, Maes $L$. Ellagic acid derivatives from Syzygium cumini stem bark: investigation of their antiplasmodial activity. Nat Prod Commun 2009; 4: 1371-1376

14 Soh NP, Witkowski B, Olagnier D, Nicolau ML, Garcia-Alvarez MC, Berry $A$, Vical $B$. In vitro and in vivo properties of ellagic acid in malaria treatment. Antimicrob Agents Chemother 2009; 53: 1100-1106

15 Clifford MN, Scalbert A. Ellagitannins - nature, and dietary burden. J Sci Food Agr 2000; 80: 1118-1125

16 Reddy MK, Cupta SK, Jacob MR, Khan SI, Ferreira D. Antioxidant, antimalaria and antimicrobial activities of tannin-rich fractions, ellagitannins and phenolic acids from Punica granatum. Planta Med 2007; 73: 461467

17 Asres K, Bucar F, Knauder E, Yardley V, Kendrick H, Croft SL. In vitro antiprotozoal activity of extract and compounds from the stem bark of Combretum molle. Phytother Res 2001; 15: 613-617

18 Wilson TC, Hagerman A. Quantitative determination of ellagicacid. J Agric Food Chem 1990; 38: 1678-1683
19 Haslam E. Natural polyphenols (vegetable tannins) as drugs: possible modes of action. J Nat Prod 1996; 59: 205-215

20 Chen PS, Li JH, Liu TY, Lin TC. Folk medicine Terminalia catappa and its major tannin component, punicalagin, are effective against bleomycininduced genotoxicity in Chinese hamster ovary cells. Cancer Lett 2000; 152: $115-122$

21 Kulkarni AP, Mahal H S, Kapoor S, Aradhya SM. In vitro studies on the binding, antioxidant, and cytotoxic actions of punicalagin. J Agric Food Chem 2007; 55: 1491-1500

22 Haidari M, Ali M, Ward Casscells III, Madjid M. Pomegranate (Punica granatum) purified polyphenol extract inhibits influenza virus and has a synergistic effect with oseltamivir. Phytomedicine 2009; 16: $1127-1136$

23 Lin CC, Hsu YF, Lin TC, Hsu HY. Antioxidant and hepatoprotective effect of punicalagin and punicalin on acetaminophen-induced liver damage in rats. Phytotherapy Research 2001; 15: 206-212

24 Filippich LJ, Zhu J, Alsalami MT. Hepatotoxicity and nephrotoxic principles in Terminalia oblongata. Res Vet Sci 1991; 50: 170-177

25 Cerda B, Ceron JJ, Barberan AT, Espin JC. Repeated oral administration of high doses of the pomegranate ellagitannin punicalagin to rats for 37 days is not toxic. J Agric Food Chem 2003; 51: 3493-3501

26 Dell'Agli M, Parapini S, Basilico N, Verotta L, Taramelli D, Berry C, Bosisio E. In vitro studies of the mechanism of action of two compounds with antiplasmodial activity. Planta Med 2003; 69: 162-164

27 Egan TJ, Marques HM. The role of haem in the activity of chloroquine and related antimalarial drugs. Coordin Chem Rev 1999; 190-192: 493-517

28 Hamad AWR, Al-Momani WM, Janakat S, Oran SA. Bioavailability of ellagic acid after single dose administration using HPLC. Pakistan Journal of Nutrition 2009; 8: 1661-1664

29 Kaur S, Grover IS, Kumar S. Antimutagenic potential of ellagic acid isolated from Terminalia arjuna. Indian J Exp Biol 1997; 35: 478-482

30 Kasimsetty SG, Bialonska D, Reddy MK, Ma G, Khan I, Ferreira D. Colon cancer chemopreventive activities of pomegranate ellagitannins and urolithins. J Agric Food Chem 2010; 58: 2180-2187

31 Rogerio AP, Fontanari C, Borducchi E, Keller AC, Russo M, Soares EG, Albuquerque DA, Faccioli LH. Anti-inflammatory effects of Lafoensia pacari and ellagic acid in a murine model of asthma. Eur J Pharmacol 2008; 580: $262-270$

32 Ruibal JI. Duplication inhibition of the human immunideficiency virus by tannin extracts from Pinus caribaea morelet. J Pharmacol 2003; 2: 37

33 Dell'Agli M, Galli GV, Bulgari M, Basilico N, Romeo S, Bhattacharya D, Taramelli D, Bosisio E. Ellagitannins of the fruit rind of pomegranate (Punica granatum) antagonize in vitro the host inflammatory response mechanisms involved in the onset of malaria. Malar J 2010; 9: 208

34 Lakovleva LV, Ivakhnenko AK, Buniatian ND. The protective action of ellagic acid in experimental myocarditis. Eksp Klin Farmakol 1998; 61: 31-34

35 Beserra AM, Calegari PI, Souza Mdo C, Dos Santos RA, Lima JC, Silva RM, Balogun SO, Martins DT. Gastroprotective and ulcer-healing mechanism of ellagic acid in experimental rats. J Agric Food Chem 2011; 59: 6957-6965

36 Singh K, Khanna AK, Chander R. Hepatoprotective effect of ellagic acid against carbon induced hepatotoxicity in rats. Indian J Exp Biol 1999; 37: $1025-1026$

37 Neuwinger HD. Afrikanische Arzneipflanzen und Jagdgifte. Stuttgart: Wissenschaftliche Verlagsgesellschaft mbH; 1998: 822-827

38 Yasumoto T, Endo M. Toxicity study on a marine snail Turbo argyrostoma. III. Occurrence of candicine. Nippon Suisan Gakkaishi 1974; 40: 841-845

39 Hori K, Yamamoto T, Miyazawa K, Ito K. Occurrence of candicine o-sulfatei in the red alga, Ahnfeltia paradoxa. B Jpn Soc Sci Fish 1980; 46: 559-562

40 Nakanishi T, Suzuki M, Mashiba A, Ishikawa K, Yokotsuka T. Synthesis of NK 109, an anticancer Benzo[c]phenanthridine alkaloid. J Org Chem 1998; 63: 4235-4239

41 Liang $M$, Zhang $W$, Hu J, Runhui L, Zhang C. Simultaneaous analysis of alkaloids from Zanthoxylum nitidum by high performance liquide chromatography-diode array detector-electrospray tandem mass spectrometry. J Pharm Biomed Anal 2006; 42: 178-183

42 Talontsi FM, Matasyoh, JC, Ngoumfo RM, Chepkorir R. Mosquito larvicidal activity of alkaloids from Zanthoxylum lemairei against the malaria vector Anopheles gambiae. Pestic Biochem Phys 2011; 99: 82-85 
43 Gakunju DM, Mberu EK, Dossaji SF, Gray AI, Waigh RD, Waterman PG, Watkins WM. Potent antimalarial activity of the alkaloid nitidine, isolated from a Kenyan herbal remedy. Antimicrob Agents Chemother 1995; 39: 2606-2609

44 Bouquet J, Rivaud M, Chevalley S, Deharo E, Jullian V, Valentin A. Biological activities of nitidine, a potential anti-malarial lead compound. Malar J 2012; 11: 67

45 Kato A, Masataka, M, Ichimaru, M, Nishiyama Y. Isolation of alkaloidal constituents of Zanthoxylum usambarense and Zanthoxylum chalybeum using ion-pair HPLC. J Nat Prod 1996; 59: 316-318

46 Tan GT, Pezzuto JM, Kinghorn AD, Hughes SH. Evaluation of natural products as inhibitors of human immunodeficiency virus type 1 (HIV-1) reverse transcriptase. J Nat Prod 1991; 54: 143-154
47 Zirihi GN, N'guessan K, Etien DT, Serikouassi B. Evaluation in vitro of antiplasmodial activity of ethanolic extracts of Funtumia elastica, Rauvolfia vomitoria and Zanthoxylum gilletii on Plasmodium falciparum isolates from Côte d'Ivoire. J Anim Plant Sci 2009; 5: 406-413

48 Fidock DA, Rosenthal PJ, Croft SL, Brun R, Nwaka S. Antimalaria drug discovery: efficicacy models for compound screening. Nat Rev Drug Discov 2004; 3: 509-520

49 Frédérich $M$, De Pauw MC, Prosperi C, Tits M, Brandt V, Penelle J, Hayette $M P$, De Mol P, Angenot L. Strychnogucines A and B, two new antiplasmodial bisindole alkaloids from Strychnos icaja. J Nat Prod 2001; 64: $12-16$ 